\title{
Analysis of the molecular features of rectal carcinoid tumors to identify new biomarkers that predict biological malignancy
}

\author{
Kei Mitsuhashi ${ }^{1, *}$, Itaru Yamamoto ${ }^{1, *}$, Hiroyoshi Kurihara ${ }^{1, *}$, Shinichi Kanno ${ }^{1, *}$, \\ Miki Ito ${ }^{1}$, Hisayoshi Igarashi ${ }^{1}$, Keisuke Ishigami ${ }^{1}$, Yasutaka Sukawa ${ }^{1,2}$, \\ Mami Tachibana ${ }^{1}$, Hiroaki Takahashi ${ }^{3}$, Takashi Tokino ${ }^{4}$, Reo Maruyama ${ }^{5}$, Hiromu \\ Suzuki ${ }^{5}$ Kohzoh Imai ${ }^{6}$, Yasuhisa Shinomura ${ }^{1}$, Hiroyuki Yamamoto ${ }^{7,+}$, Katsuhiko \\ Nosho $^{1,+}$ \\ ${ }^{1}$ Department of Gastroenterology, Rheumatology and Clinical Immunology, Sapporo Medical University School of Medicine, \\ Sapporo, Japan \\ ${ }^{2}$ Department of Medical Oncology, Dana-Farber Cancer Institute and Harvard Medical School, Boston, MA, USA \\ ${ }^{3}$ Department of Gastroenterology, Keiyukai Daini Hospital, Sapporo, Japan \\ ${ }^{4}$ Department of Medical Genome Sciences, Research Institute for Frontier Medicine, Sapporo Medical University School of \\ Medicine, Sapporo, Japan \\ ${ }^{5}$ Department of Molecular Biology, Sapporo Medical University School of Medicine, Sapporo, Japan \\ ${ }^{6}$ The Institute of Medical Science, The University of Tokyo, Tokyo, Japan \\ ${ }^{7}$ Department of Gastroenterology and Hepatology, St. Marianna University School of Medicine, Kawasaki, Japan \\ *These authors have contributed equally to this work \\ †These authors have contributed equally to this work \\ Correspondence to: \\ Katsuhiko Nosho, e-mail: nosho@sapmed.ac.jp \\ Keywords: carcinoid, non-coding RNA, epigenetics, neuroendocrine tumor, rectum \\ Received: April 01,2015 Accepted: June 05, $2015 \quad$ Published: June 17, 2015
}

\section{ABSTRACT}

Although gastrointestinal carcinoid tumors are relatively rare in the digestive tract, a quarter of them are present in the rectum. In the absence of specific tumor biomarkers, lymphatic or vascular invasion is generally used to predict the risk of lymph node metastasis. We, therefore, examined the genetic and epigenetic alterations potentially associated with lymphovascular invasion among $\mathbf{5 6}$ patients with rectal carcinoid tumors. We also conducted a microRNA (miRNA) array analysis. Our analysis failed to detect mutations in BRAF, KRAS, NRAS, or PIK3CA or any microsatellite instability (MSI); however, we did observe CpG island methylator phenotype (CIMP) positivity in $13 \%(7 / 56)$ of the carcinoid tumors. The CIMP-positive status was significantly correlated with lymphovascular invasion $(P=0.036)$. The array analysis revealed that microRNA-885 (miR-885)-5p was the most up-regulated miRNA in the carcinoid tumors with lymphovascular invasion compared with that in those without invasion. In addition, high miR-885-5p expression was independently associated with lymphovascular invasion $(P=0.0002)$. In conclusion, our findings suggest that miR-885-5p and CIMP status may be useful biomarkers for predicting biological malignancy in patients with rectal carcinoid tumors.

\section{INTRODUCTION}

Carcinoid tumors originate from neuroendocrine cells and grow slowly. Although they are relatively rare in the digestive tract, rectal carcinoid tumors account for a quarter of the gastrointestinal carcinoid tumors. Carcinoid tumors are classified as neuroendocrine tumor-grade 1 (NET-G1) tumors, according to the 2010 revision of the World Health Organization (WHO) guidelines [1]. In the absence of specific tumor biomarkers, the presence of lymphatic or vascular invasion is generally used to predict the risk of lymph node metastasis after endoscopic resection. 
Therefore, we examined the clinical, pathological, and molecular features of rectal carcinoid tumors to identify new biomarkers that were predictive of malignancy.

MicroRNAs (miRNAs) are a class of small non-coding RNA molecules that function as posttranscriptional gene regulators, playing a central role as master regulators of gene expression in multiple cancer-related signaling pathways, including invasion and metastasis [2-18]. Using miRNA array analysis, we recently discovered that microRNA-31 (miR-31) expression is significantly up-regulated in $B R A F$-mutated colorectal cancers compared with that in wild-type colorectal cancers [2]. Moreover, associations were identified between miR-31 expression, proximal tumor location, and poor prognosis for colorectal cancers. Nevertheless, no previous study has reported its role in the progression of rectal carcinoid tumors.

The term "the $\mathrm{CpG}$ island methylator phenotype (CIMP)" has been repeatedly used over the past decade to describe $\mathrm{CpG}$ island promoter methylation in various human malignancies [19-34]. CIMP represents a distinct form of epigenetic instability in colorectal cancer, $[3,21$, 35-37] causing most sporadic colorectal cancers with microsatellite instability (MSI) through the epigenetic inactivation of $M L H 1$. However, no study has reported the epigenetic alterations, including CIMP status, associated with rectal carcinoid tumors.

Therefore, we examined which molecular changes could represent new biomarkers of malignancy in rectal carcinoid tumors. To identify the associations, we analyzed the genetic and epigenetic alterations according to lymphovascular (lymphatic or vascular) invasion status using a database of 56 cases of rectal carcinoid tumors. We also conducted miRNA array analysis to detect the miRNA molecules that are potentially associated with lymphovascular invasion.

\section{RESULTS}

\section{Genetic and epigenetic alterations in rectal carcinoid tumors}

None of the BRAF, KRAS, NRAS, or PIK3CA mutations were detected in the carcinoid tumors; moreover, none of the 56 cases exhibited MSI-high status. With regard to the epigenetic alterations, $C A C N A 1 G, C D K N 2 A$ (p16), IGFBP7, IGF2, MGMT, MINT1, MINT2, MINT31, MLH1, RASSF2, and RUNX3 methylations were sequentially detected in $1(1.8 \%), 18(32 \%), 0(0 \%), 7(13 \%), 1(1.8 \%)$, $28(50 \%), 15(27 \%), 34(61 \%), 3(5.4 \%), 1(1.8 \%)$, and $0(0 \%)$ rectal carcinoid tumors, respectively (Figure 1$)$.

\section{The association between lymphovascular invasion and clinical and molecular features in rectal carcinoid tumors}

Table 1 shows the association between lymphovascular invasion and clinical and molecular features in carcinoid tumors. Neither age nor gender was correlated with lymphovascular invasion. With regard to the molecular features, IGF2 $(P=0.036)$, MINT31 $(P=0.034)$, and MLH1 $(P=0.0022)$ methylations were significantly correlated with lymphovascular invasion.

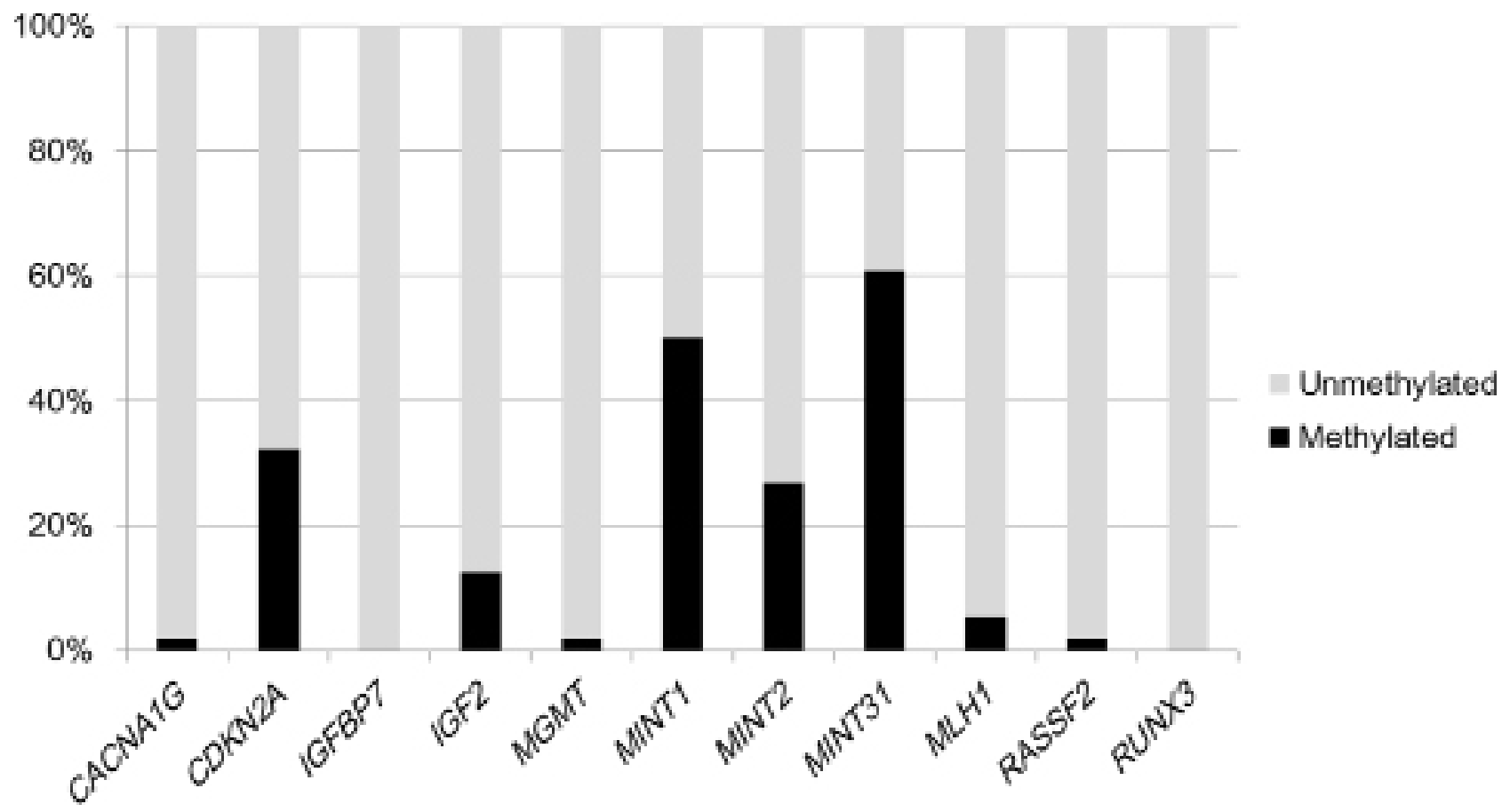

Figure 1: Frequencies of CACNA1G, CDKN2A (p16), IGFBP7, IGF2, MGMT, MINT1, MINT2, MINT31, MLH1, $R A S S F 2$, and $R U N X 3$ methylations in 56 rectal carcinoid tumors. 
Table 1: Clinical and molecular features of rectal carcinoid tumors by lymphovascular invasion

\begin{tabular}{|c|c|c|c|c|}
\hline \multirow{2}{*}{$\begin{array}{c}\text { Clinical and } \\
\text { molecular feature }\end{array}$} & \multirow{2}{*}{ Total } & \multicolumn{2}{|c|}{ Lymphovascular invasion } & \multirow{2}{*}{$\boldsymbol{P}$} \\
\hline & & Negative & Positive & \\
\hline All cases & 56 & 43 & 13 & \\
\hline \multicolumn{5}{|l|}{ Gender } \\
\hline Male & $29(52 \%)$ & $21(49 \%)$ & $8(62 \%)$ & 0.42 \\
\hline Female & $27(48 \%)$ & $22(51 \%)$ & $5(38 \%)$ & \\
\hline Age $($ mean \pm SD) & $58.9 \pm 13.9$ & $58.3 \pm 2.1$ & $61.0 \pm 3.8$ & 0.53 \\
\hline $\begin{array}{l}\text { Tumor size }(\mathrm{mm}) \\
(\text { mean } \pm \mathrm{SD})\end{array}$ & $6.2 \pm 2.5$ & $5.9 \pm 0.37$ & $7.0 \pm 0.68$ & 0.17 \\
\hline \multicolumn{5}{|l|}{$B R A F(\operatorname{codon} 600)$} \\
\hline Wild-type & $56(100 \%)$ & $43(100 \%)$ & $13(0 \%)$ & N/A \\
\hline Mutated & $0(0 \%)$ & $0(0 \%)$ & $0(0 \%)$ & \\
\hline \multicolumn{5}{|l|}{$\begin{array}{l}K R A S \text { (codon } 12,13, \\
61, \text { or } 146)\end{array}$} \\
\hline Wild-type & $56(100 \%)$ & $43(100 \%)$ & $13(0 \%)$ & $\mathrm{N} / \mathrm{A}$ \\
\hline Mutated & $0(0 \%)$ & $0(0 \%)$ & $0(0 \%)$ & \\
\hline \multicolumn{5}{|l|}{$\begin{array}{l}\text { NRAS (codon 12, 13, } \\
\text { or } 61)\end{array}$} \\
\hline Wild-type & $56(100 \%)$ & $43(100 \%)$ & $13(0 \%)$ & N/A \\
\hline Mutated & $0(0 \%)$ & $0(0 \%)$ & $0(0 \%)$ & \\
\hline \multicolumn{5}{|l|}{ PIK3CA (exon 9 or 20$)$} \\
\hline Wild-type & $56(100 \%)$ & $43(100 \%)$ & $13(0 \%)$ & $\mathrm{N} / \mathrm{A}$ \\
\hline Mutated & $0(0 \%)$ & $0(0 \%)$ & $0(0 \%)$ & \\
\hline \multicolumn{5}{|l|}{ CACNA1G } \\
\hline Unmethylated & $55(98 \%)$ & $42(98 \%)$ & $13(100 \%)$ & 0.47 \\
\hline Methylated & $1(1.8 \%)$ & $1(2.3 \%)$ & $0(0 \%)$ & \\
\hline \multicolumn{5}{|l|}{$C D K N 2 A(p 16)$} \\
\hline Unmethylated & $38(68 \%)$ & $32(74 \%)$ & $6(46 \%)$ & 0.062 \\
\hline Methylated & $18(32 \%)$ & $11(26 \%)$ & $7(54 \%)$ & \\
\hline \multicolumn{5}{|l|}{$I G F B P 7$} \\
\hline Unmethylated & $56(100 \%)$ & $43(100 \%)$ & $13(0 \%)$ & $\mathrm{N} / \mathrm{A}$ \\
\hline Methylated & $0(0 \%)$ & $0(0 \%)$ & $0(0 \%)$ & \\
\hline \multicolumn{5}{|l|}{$I G F 2$} \\
\hline Unmethylated & $49(87 \%)$ & $40(93 \%)$ & $9(69 \%)$ & 0.036 \\
\hline Methylated & $7(13 \%)$ & $3(7.0 \%)$ & $4(31 \%)$ & \\
\hline \multicolumn{5}{|l|}{$M G M T$} \\
\hline Unmethylated & $55(98 \%)$ & $43(100 \%)$ & $12(92 \%)$ & 0.084 \\
\hline Methylated & $1(1.8 \%)$ & $0(0 \%)$ & $1(7.7 \%)$ & \\
\hline
\end{tabular}

(Continued) 


\begin{tabular}{|c|c|c|c|c|}
\hline \multirow{2}{*}{$\begin{array}{c}\text { Clinical and } \\
\text { molecular feature }\end{array}$} & \multirow{2}{*}{ Total } & \multicolumn{2}{|c|}{ Lymphovascular invasion } & \multirow{2}{*}{$\boldsymbol{P}$} \\
\hline & & Negative & Positive & \\
\hline \multicolumn{5}{|l|}{ MINT1 } \\
\hline Unmethylated & $28(50 \%)$ & $22(51 \%)$ & $6(46 \%)$ & 0.75 \\
\hline Methylated & $28(50 \%)$ & $21(49 \%)$ & $7(54 \%)$ & \\
\hline \multicolumn{5}{|l|}{ MINT2 } \\
\hline Unmethylated & $41(73 \%)$ & $33(77 \%)$ & $8(62 \%)$ & 0.29 \\
\hline Methylated & $15(27 \%)$ & $10(23 \%)$ & $5(38 \%)$ & \\
\hline \multicolumn{5}{|l|}{ MINT31 } \\
\hline Unmethylated & $22(39 \%)$ & $20(47 \%)$ & $2(15 \%)$ & 0.034 \\
\hline Methylated & $34(61 \%)$ & $23(53 \%)$ & $11(85 \%)$ & \\
\hline \multicolumn{5}{|l|}{ MLH1 } \\
\hline Unmethylated & $53(95 \%)$ & $43(100 \%)$ & $10(77 \%)$ & 0.0022 \\
\hline Methylated & $3(5.4 \%)$ & $0(0 \%)$ & $3(23 \%)$ & \\
\hline \multicolumn{5}{|l|}{ RASSF2 } \\
\hline Unmethylated & $55(98 \%)$ & $43(100 \%)$ & $12(92 \%)$ & 0.084 \\
\hline Methylated & $1(1.8 \%)$ & $0(0 \%)$ & $1(7.7 \%)$ & \\
\hline \multicolumn{5}{|l|}{$R U N X 3$} \\
\hline Unmethylated & $56(100 \%)$ & $43(100 \%)$ & $13(100 \%)$ & N/A \\
\hline Methylated & $0(0 \%)$ & $0(0 \%)$ & $0(0 \%)$ & \\
\hline \multicolumn{5}{|l|}{ CIMP status } \\
\hline CIMP negative & $49(87 \%)$ & $40(93 \%)$ & $9(69 \%)$ & 0.036 \\
\hline CIMP positive & $7(13 \%)$ & $3(7 \%)$ & $4(31 \%)$ & \\
\hline \multicolumn{5}{|l|}{ MSI status } \\
\hline MSI-low/MSS & $56(100 \%)$ & $43(100 \%)$ & $13(100 \%)$ & N/A \\
\hline MSI-high & $0(0 \%)$ & $0(0 \%)$ & $0(0 \%)$ & \\
\hline
\end{tabular}

Percentages (\%) indicate the proportion of cases with a specific clinical or molecular feature within a given dichotomous category of lymphovascular invasion status. CIMP positivity was defined as the presence of four or more of the six methylated promoters [CDKN2A (p16), IGF2, MINT1, MINT2, MINT31, and MLH1]. The $P$-values were calculated using $t$-test for age and tumor size and by means of the $\chi^{2}$ test or Fisher's exact test for all other variables.

CIMP, CpG island methylator phenotype; MSI, microsatellite instability; N/A, not applicable; SD, standard deviation.

\section{The association between lymphovascular invasion and CIMP status in rectal carcinoid tumors}

We selected the six markers $[C D K N 2 A(p 16)$, IGF2, MLH1, MINT1, MINT2, and MINT31] that were methylated in more than $5 \%$ of the rectal carcinoid tumors as CIMP markers. CIMP-positive status was defined as the presence of four or more of the six methylated promoters and CIMP-negative status as zero to three of the six methylated promoters. The CIMP-positive cases were detected in $13 \%(8 / 56)$ of the rectal carcinoid tumors, and the CIMP status was significantly correlated with lymphovascular invasion $(P=0.036)$ (Table 1$)$.

\section{Detection of high microRNA-885-5p expression in rectal carcinoid tumors with lymphovascular invasion on miRNA array analysis}

To examine the miRNA expression signature in rectal carcinoid tumors with lymphovascular invasion, 10 carcinoid tumors were randomly selected from the carcinoid tumor specimens for miRNA array analysis. Lymphovascular invasion was positive in five cases and 
negative in five. The median expression levels in the carcinoid tumors with lymphovascular invasion were compared with those in the tumors without invasion. The miRNA array data revealed different expression levels in individual miRNAs between the two groups. Ten miRNAs that displayed higher expression levels ( $\geq 30$-fold change) in carcinoid tumors with lymphovascular invasion than those without invasion are shown in Table 2. Of the 760 miRNAs, microRNA-885 (miR-885)-5p was the most up-regulated in the carcinoid tumors with lymphovascular invasion compared with that in those without invasion (878-fold change, $P=0.037$ ).

\section{Distribution of miR-885-5p expression in rectal carcinoid tumors and its association with clinical and molecular features}

We assessed all cases of 56 rectal carcinoid tumors based on the availability of miR-885-5p expression levels quantified in the carcinoid tumor and paired normal mucosa specimens. The expression of miR-885-5p was calculated using the equation $2^{-\Delta \mathrm{CT}}$, where $\Delta \mathrm{C}_{\mathrm{T}}=\left(\mathrm{C}_{\mathrm{T}}\right.$ miR-885 $\left.-\mathrm{C}_{\mathrm{T}} \mathrm{U} 6\right)$. To calculate the relative expression of miR-885-5p in each carcinoid tumor, $2^{-\Delta \mathrm{CT}}$ of the tumor tissue was divided by $2^{-\Delta \mathrm{CT}}$ of paired normal tissue. The distributions of miR885-5p expression across the 56 tumor specimens were as follows: mean, 135.0; median, 67.1; standard deviation (SD), 148.5; range, 4.3-538.2; interquartile range, 20.6-188.9. The cases with miR-885-5p expression were then divided into quartiles for further analysis: Q1 (<20.6), Q2 (20.6-67.0), Q3 (67.1-188.8), and Q4 ( $\geq 188.9)$. Table 3 shows the clinical features of the carcinoid tumors according to their miR-885-5p expression level. High miR-885-5p expression was significantly correlated with lymphovascular invasion $(P<0.0001)$ but not with gender, age, or tumor size. With regard to epigenetic alterations, $M L H 1$ methylation was only significantly associated with miR-885-5p expression $(P=0.0090)$.

\section{Multivariate analysis to identify the association with lymphovascular invasion in carcinoid tumors}

To account for multiple hypothesis testing in associations between the lymphovascular invasion status and the other five covariates (gender, age, tumor size, CIMP status, and miR-885-5p), the $P$-value was adjusted by Bonferroni correction to $P=0.01(=0.05 / 5)$. A backward stepwise elimination with a threshold of $P=0.20$ was used to select variables in the final model. Of the variables, only CIMP status and miR-885-5p were included in the final model, which showed that

\section{Table 2: Differentially expressed microRNAs in lymphovascular invasion positive and negative rectal carcinoid tumors by microRNA array analysis}

\begin{tabular}{|c|c|c|c|c|c|}
\hline \multirow{3}{*}{ No. } & \multirow{3}{*}{$\begin{array}{l}\text { Name of } \\
\text { microRNA(miR Base ID) }\end{array}$} & \multicolumn{3}{|c|}{ Relative microRNA expression (microRNA/U6) } & \multirow[b]{3}{*}{$P$} \\
\hline & & \multicolumn{2}{|c|}{ Lymphovascular invasion } & \multirow{2}{*}{$\begin{array}{c}\text { Fold change } \\
\text { (Positive group / } \\
\text { Negative group) }\end{array}$} & \\
\hline & & $\begin{array}{l}\text { Negative group } \\
\text { (median; } N=5 \text { ) }\end{array}$ & $\begin{array}{l}\text { Positive group } \\
\text { (median; } N=5 \text { ) }\end{array}$ & & \\
\hline 1 & hsa-miR-885-5p & 0.053 & 46.6 & 878 & 0.037 \\
\hline 2 & hsa-miR-216b & 0.032 & 5.9 & 187 & 0.32 \\
\hline 3 & hsa-miR-204 & 0.27 & 43.6 & 160 & 0.057 \\
\hline 4 & hsa-miR-198 & 1.3 & 159.5 & 122 & 0.17 \\
\hline 5 & hsa-miR-135a & 6.0 & 582.0 & 96 & 0.049 \\
\hline 6 & hsa-miR-452 & 0.39 & 15.9 & 41 & 0.79 \\
\hline 7 & hsa-miR-216a & 0.0012 & 0.047 & 38 & 0.15 \\
\hline 8 & hsa-miR-486-3p & 0.39 & 14.6 & 38 & 0.024 \\
\hline 9 & mmu-miR-499 & 0.36 & 13.4 & 38 & 0.056 \\
\hline 10 & hsa-miR-146b-3p & 0.44 & 14.6 & 33 & 0.083 \\
\hline
\end{tabular}

The fold change is expressed as the median of that for the rectal carcinoid tumors with lymphovascular invasion divided by those without lymphovascular invasion for each microRNA. $P$-values were determined by the Mann-Whitney $U$ test. 
Table 3: Clinicopathological and molecular features of rectal carcinoid tumors by miR-885-5p expression

\begin{tabular}{|c|c|c|c|c|}
\hline \multirow{2}{*}{$\begin{array}{l}\text { Clinicopathological and } \\
\text { molecular feature }\end{array}$} & \multirow{2}{*}{ Total } & \multicolumn{2}{|c|}{ miR-885-5p } & \multirow{2}{*}{$P$} \\
\hline & & Low expression & High expression & \\
\hline All cases & 56 & 51 & 5 & \\
\hline \multicolumn{5}{|l|}{ Gender } \\
\hline Male & $29(52 \%)$ & $26(51 \%)$ & $3(60 \%)$ & 0.70 \\
\hline Female & $27(48 \%)$ & $25(49 \%)$ & $2(40 \%)$ & \\
\hline Age $($ mean \pm SD) & $58.9 \pm 13.9$ & $57.2 \pm 6.2$ & $59.1 \pm 1.9$ & 0.78 \\
\hline $\begin{array}{l}\text { Tumor size }(\mathrm{mm}) \\
(\text { mean } \pm \mathrm{SD})\end{array}$ & $6.2 \pm 2.5$ & $7.0 \pm 1.1$ & $6.1 \pm 0.35$ & 0.44 \\
\hline \multicolumn{5}{|l|}{ Lymphovascular invasion } \\
\hline Negative & $43(77 \%)$ & $43(84 \%)$ & $0(0 \%)$ & $<0.0001$ \\
\hline Positive & $13(23 \%)$ & $8(16 \%)$ & $5(100 \%)$ & \\
\hline \multicolumn{5}{|l|}{$C D K N 2 A(p 16)$} \\
\hline Unmethylated & $38(68 \%)$ & $36(71 \%)$ & $2(40 \%)$ & 0.18 \\
\hline Methylated & $18(32 \%)$ & $15(29 \%)$ & $3(60 \%)$ & \\
\hline \multicolumn{5}{|l|}{$I G F 2$} \\
\hline Unmethylated & $49(87 \%)$ & $46(90 \%)$ & $3(60 \%)$ & 0.097 \\
\hline Methylated & $7(13 \%)$ & $5(9.8 \%)$ & $2(40 \%)$ & \\
\hline \multicolumn{5}{|l|}{ MINT1 } \\
\hline Unmethylated & $28(50 \%)$ & $25(49 \%)$ & $3(60 \%)$ & 0.64 \\
\hline Methylated & $28(50 \%)$ & $26(51 \%)$ & $2(40 \%)$ & \\
\hline \multicolumn{5}{|l|}{ MINT2 } \\
\hline Unmethylated & $41(73 \%)$ & $38(75 \%)$ & $3(60 \%)$ & 0.50 \\
\hline Methylated & $15(27 \%)$ & $13(25 \%)$ & $2(40 \%)$ & \\
\hline \multicolumn{5}{|l|}{ MINT31 } \\
\hline Unmethylated & $22(39 \%)$ & $20(39 \%)$ & $2(40 \%)$ & 0.97 \\
\hline Methylated & $34(61 \%)$ & $31(61 \%)$ & $3(60 \%)$ & \\
\hline \multicolumn{5}{|l|}{ MLH1 } \\
\hline Unmethylated & $53(95 \%)$ & $50(98 \%)$ & $3(60 \%)$ & 0.0090 \\
\hline Methylated & $3(5.3 \%)$ & $1(2.0 \%)$ & $2(40 \%)$ & \\
\hline \multicolumn{5}{|l|}{ CIMP status } \\
\hline Negative & $7(13 \%)$ & $5(9.8 \%)$ & $2(40 \%)$ & 0.098 \\
\hline Positive & $49(87 \%)$ & $46(90 \%)$ & $3(60 \%)$ & \\
\hline
\end{tabular}

Percentage (\%) indicates the proportion of cases with a specific clinicopathological or molecular feature according to miR-885-5p expression status. CIMP positivity was defined as the presence of four or more of the six methylated promoters [CDKN2A (p16), IGF2, MINT1, MINT2, MINT31, and MLH1]. $P$-values were calculated by $t$-test for age and tumor size and by a chi-square test or Fisher's exact test for all other variables.

CIMP, CpG island methylator phenotype; miR-885, microRNA-885; SD, standard deviation. 
lymphovascular invasion was only significantly associated with high miR-885-5p expression $(P=0.0002)$.

\section{DISCUSSION}

We examined the genetic and epigenetic alterations associated with lymphovascular invasion and conducted miRNA array analysis among 56 patients with rectal carcinoid tumors and who underwent endoscopic resection. We did not detect KRAS, BRAF, or PIK3CA mutations or MSI-high in the carcinoid tumors. With regard to the epigenetic alterations, CIMP positivity was present in 13\% (7/56) of the rectal carcinoid tumors and was significantly correlated with lymphovascular invasion. The miRNA array analysis revealed that miR-885-5p was the most up-regulated miRNA in the rectal carcinoid tumors with lymphovascular invasion compared with that in those without invasion. Our data also showed that high miR-885-5p expression was independently associated with lymphovascular invasion.

Given that miRNAs can function as oncogenes or tumor suppressors, they are increasingly being recognized as useful biomarkers for various human cancers [13-18]. In colorectal cancers, several miRNAs are known to be deregulated $[2-12,38-40]$ with target genes in the downstream effectors of epidermal growth factor receptor (EGFR) [2, 9, 41, 42]. With regard to premalignant colorectal lesions, we recently noted that high miR-31 expression is frequently detected in cases with serrated lesions [sessile serrated adenoma/polyp (SSA/P) and traditional serrated adenoma] than in non-serrated adenomas, suggesting an association between miR-31 expression and the serrated pathway [3].

In this study, specific miRNA expression associated with lymphovascular invasion was identified in the rectal carcinoid tumors. Using miRNA array analysis, our data showed that miR-885-5p expression was the most up-regulated miRNA in the carcinoid tumors with lymphovascular invasion compared with that in those without invasion (878-fold change). In the current study, we found that high miR-885-5p expression was independently associated with lymphovascular invasion in a sample of 56 patients with rectal carcinoid tumors. To our knowledge, this is therefore the first report that has identified an association between miR-885-5p expression and lymphovascular invasion in rectal carcinoid tumors.

MiR-885-5p is located in the $3 p 25.3$ genomic region. A previous study reported that the up-regulation of miR-885-5p reduced the levels of MMP-9 in glioma cells and that it inhibited cellular invasion [43]. Furthermore, the transfection of miR $885-5 p$ mimics could decrease MMP-9 expression. Because MMP-9 is known to play a pivotal role in regulating invasiveness in various human cancers, miR-885-5p may increase for inhibiting tumor cell invasion via MMP-9 in rectal carcinoid tumors.
Our current study was limited by the cross-sectional design and the potential for bias (i.e., selection bias) that could have confounded the results. Nevertheless, our multivariate regression analysis was adjusted for potential clinical and molecular confounders. Although further study is needed to confirm our results, this is an interesting first step toward the improved understanding and diagnosis of these rare tumors.

With regard to colorectal cancer, a recent miRNA array analysis reported that miR-885-5p is significantly up-regulated in liver metastases compared with that in primary colorectal cancer tissue, and high serum miR-885-5p expression significantly predicts survival and metastasis in patients with colorectal cancer [44]. Although miR-885-5p expression in primary colorectal cancer tissue was not previously associated with clinical and pathological features, high serum miR-885-5p is significantly associated with both poor overall survival and poor disease-free survival [44]. Using in situ hybridization analysis, Hur et al. have also confirmed miR-885-5p expression in metastatic tumor cells of the liver, but not in their adjacent hepatocytes; however, they did not utilize laser capture microdissection, which might decrease the influence of stromal cells [44]. When Iino et al. used laser capture microdissection to isolate cancer cells from formalin-fixed paraffin-embedded (FFPE) primary colorectal cancer samples and corresponding metastatic liver tumors, they identified miR-885-5p as the second most up-regulated miRNA in colorectal liver metastases compared with primary tumors [45]. These findings suggest that the up-regulation of miR-885-5p in tumor cells, but not in stromal cells, may play an important role in the development of colorectal liver metastasis.

CIMP is associated with both favorable and unfavorable prognoses, as well as different clinical characteristics, depending on the tumor type. In colorectal cancer, CIMP is associated with a favorable prognosis $[35,46]$. In contrast, a recent analysis in patients with primary clear cell renal carcinoma showed that CIMP positivity is characterized by tumor clusters that are associated with aggressiveness and patient survival [34]. Regarding early colorectal neoplastic lesions, we recently reported that there was a progressive increase in the methylation status (i.e., CIMP status and MLH1 methylation) from hyperplastic polyps to $\mathrm{SSA} / \mathrm{Ps}$ to SSA/Ps with cytological dysplasia [3], suggesting that accumulating epigenetic alterations may be associated with biological malignancy in serrated pathway progression. Such findings emphasize the motivation for establishing whether CIMP is universal or cancer specific because of its potential for use as a prognostic marker. There are several possible explanations for the discrepancies identified to date. First, although CIMP has been identified in different tumors, it may simply not be a universal marker of good or bad prognosis. Second, it is 
possible that the gene panels and cut-off thresholds used to define CIMP are not sufficiently accurate to define the true phenotypes of some cancers.

In contrast to colorectal cancer, research into CIMP in rectal carcinoid tumors is unfamiliar. In the current study, we examined 11 methylated promoters. CIMP positivity was defined as the presence of four or more of the six methylated promoters $[C D K N 2 A$ (p16), IGF2, MINT1, MINT2, MINT31, and MLH1], which was detected in $13 \%$ of the rectal carcinoid tumors and was associated with lymphovascular invasion. These results suggest that some epigenetic alterations were associated with biological malignancy in rectal carcinoid tumors.

The BRAF, KRAS, and NRAS mutations are widely recognized to be the major causes of RAS/ $\mathrm{RAF} / \mathrm{MEK} / \mathrm{ERK}$ pathway dysregulation in colorectal cancer [2, 9, 41, 42]. Previous studies reported that $B R A F, K R A S$, and NRAS mutations occur in $10 \%-15 \%$ $[2,35,36,47], 35-40 \%[36,37,42,48]$, and $2-7 \%$ of colorectal cancers $[42,49]$, respectively. The PIK3CA gene encodes the catalytic subunit p110 alpha of PI3K. Mutant PIK3CA stimulates the PI3K/AKT pathway and promotes cell growth in various cancers, including colorectal cancer. PIK3CA (exon 9 and 20) mutations have been described in $15-18 \%$ of colorectal cancers $[47,50]$. In the current study, we found no evidence of the $B R A F, K R A S, N R A S$, or PIK3CA mutations in rectal carcinoid tumors, suggesting that neither the RAS/RAF/ $\mathrm{MEK} / \mathrm{ERK}$ pathway nor the PI3K/AKT pathway were associated with tumorigenesis and disease progression in those tumors.

In conclusion, we demonstrated that CIMP positivity was significantly correlated with lymphovascular invasion in rectal carcinoid tumors. Furthermore, miR-885-5p was independently associated with lymphovascular invasion in carcinoid tumors. Thus, our findings suggest that miR-885-5p and CIMP status may be useful biomarkers for predicting biological malignancy in patients with rectal carcinoid tumors.

\section{MATERIALS AND METHODS}

\section{Patients and rectal carcinoid tumor tissue specimens}

We collected formalin-fixed paraffin-embedded (FFPE) tissue specimens from 56 cases of rectal carcinoid tumors following endoscopic resection at Sapporo Medical University Hospital or Keiyukai Sapporo Hospital between 2007 and 2014. To minimize selection bias, we collected consecutive FFPE tissue specimens. All lesions were submucosal with smooth surfaces and yellow tones, pathologically corresponding to the WHO NET-G1 classification [1].

Lymphovascular (lymphatic or vascular) invasion was detected in $23 \%(13 / 56)$ of the rectal carcinoid tumors. Of the 13 cases with lymphovascular invasion, surgical resections were treated in 7 cases. Several cases $(N=6)$ were followed without surgical resection because informed consent was not obtained from those patients. Lymphovascular invasion was used as a surrogate marker of the malignancy potential. No patient exhibited recurrence or death associated with carcinoid tumor until December 2014.

Informed consent was obtained from all the patients before specimen collection. This study was approved by the institutional review boards of the participating institutions and complied with the tenets of the Helsinki Declaration. Our analysis of the rectal carcinoid tumor tissue specimens is fully compliant with the REMARK guidelines [51].

\section{Pyrosequencing of $B R A F, K R A S, N R A S$, and $P I K 3 C A$ and analysis of MSI}

Genomic DNA was used for PCR and targeted pyrosequencing of $B R A F$ (codon 600), KRAS (codon 12, 13, 61, or 146), NRAS (codon 12, 13, or 61), and PIK3CA (exon 9 or 20) as previously described [2, 42, 47, 49, $50,52]$. MSI analysis was performed using two markers (BAT25 and BAT26) as previously described [2, 48].

\section{Sodium bisulfite treatment and Real-Time PCR (MethyLight) to assess promoter methylation of CACNA1G, CDKN2A (p16), IGFBP7, IGF2, MGMT, MINT1, MINT2, MINT31, MLH1, $R A S S F 2$, and $R U N X 3$}

Bisulfite modification of genomic DNA was performed using the BisulFlash ${ }^{\mathrm{TM}}$ DNA Modification Kit (Epigentek, Brooklyn, NY, USA) [3]. DNA methylation was quantified in 11 promoters [CACNA1G, CDKN2A (p16), IGFBP7, IGF2, MGMT, MINT1, MINT2, MINT31, MLH1, RASSF2, and RUNX3] using Real-Time PCR (MethyLight) as previously described [35-37, 48]. The percentage of methylated reference (i.e., methylation index) at a specific locus was calculated as previously described [35, 36, 53]. Methylation positivity was defined as the percentage of methylated reference $\geq 4$ as previously validated $[35,36,53]$.

\section{RNA extraction and microRNA array analysis}

Total RNA was extracted from FFPE tissues using the miRNeasy FFPE Kit (Qiagen, Valencia, CA, USA). The TaqMan ${ }^{\circledR}$ Array Human MicroRNA A + B Cards Set v3.0 (Applied Biosystems, Foster City, CA, USA) was used for simultaneous measurement of the expression of 760 miRNAs on a microfluidic PCR platform. In brief, $1 \mu \mathrm{g}$ of total RNA was reverse transcribed using the Megaplex Pools Kit (Applied Biosystems), following which miRNAs were amplified and detected 
by PCR with specific primers and TaqMan probes. PCR was run in the $7900 \mathrm{HT}$ Fast Real-Time PCR system (Applied Biosystems), and SDS 2.2.2 software (Applied Biosystems) was used for comparative analysis of the cycle threshold $\left(\Delta \mathrm{C}_{\mathrm{T}}\right)$. U6 snRNA (RNU6B; Applied Biosystems) served as an endogenous control. $\Delta \mathrm{C}_{\mathrm{T}}$ was calculated by subtracting the $\mathrm{C}_{\mathrm{T}}$ values of $\mathrm{U} 6$ from the $\mathrm{C}_{\mathrm{T}}$ values of the gene of interest. Expression of each miRNA in the tumor samples was calculated using the equation $2^{-\Delta \mathrm{CT}}$, where $\Delta \mathrm{C}_{\mathrm{T}}=\left(\mathrm{C}_{\mathrm{T}}\right.$ miRNA $\left.-\mathrm{C}_{\mathrm{T}} \mathrm{U} 6\right)$.

\section{Quantitative reverse transcription-PCR (RT-PCR) of microRNA-885-5p}

MiR-885-5p expression levels were analyzed by quantitative RT-PCR using the TaqMan MicroRNA Reverse Transcription Kit (Applied Biosystems) and TaqMan microRNA Assays (Applied Biosystems) as previously described [2]. U6 small nuclear RNA (snRNA; RNU6B; Applied Biosystems) served as an endogenous control. We defined high expression level groups of miR$885-5 p$ as the fourth level (Q4) in a quartile as described previously [2].

\section{Statistical analysis}

The JMP (version 10) software was used for all statistical analyses (SAS Institute, Cary, NC, USA). $P$ values were two-sided. Univariate analysis was performed to determine the clinical and molecular characteristics according to the lymphovascular invasion of the rectal carcinoid tumors. $P$ values were calculated using $t$-test for age and tumor size and by a chi-square test or Fisher's exact test for all other variables.

A multivariate logistic regression analysis assessing the relationships with lymphovascular invasion status initially included gender (male vs. female), age (continuous), tumor size (continuous), CIMP status (positive vs. negative) and miR-885-5p expression (high expression vs. low expression), considering potential confounding and causal relationships.

\section{ACKNOWLEDGMENTS}

We deeply thank the pathology departments of Sapporo Medical University Hospital and Keiyukai Sapporo Hospital for providing us with tissue specimens.

\section{CONFLICTS OF INTEREST}

No conflicts of interest.

\section{GRANT SUPPORT}

This work was supported by Ono Cancer Research Foundation (to K.N.), Takeda Science Foundation (to K.N.), Sapporo Jikeikai Tomoiki Foundation (to K.N.), The Suhara Memorial Foundation (to K.N.), and The Japanese Society of Gastroenterology Research Foundation (to K.N.).

\section{Author contributions}

Study concept and design; K.M., I.Y., K.N.

Acquisition of data; K.M., I.Y., H.K., S.K., M.I., H.I., K.I., M.T.

Analysis and interpretation of data; K.M., K.N., T.T. Drafting of the manuscript; K.M., K.N.

Critical revision of the manuscript for important intellectual content; K.M., I.Y., R.M., H.S., K.N.

Statistical analysis; K.M., K.N., Y.S.

Material support; K.M., H.K., H.T.

Study supervision; K.I., H.Y., Y.S., K.N

Final approval of manuscript; All authors

\section{Abbreviations}

CIMP, CpG island methylator phenotype; EGFR, epidermal growth factor receptor; FFPE, formalinfixed paraffin-embedded; miRNA, microRNA; miR-31, microRNA-31; miR-885, microRNA-885; MSI, microsatellite instability; NET-G1, neuroendocrine tumor-grade 1; RT-PCR, reverse transcription-PCR; $\mathrm{SD}$, standard deviation; SSA/P, sessile serrated adenoma/ polyp; WHO, World Health Organization

\section{REFERENCES}

1. Bosman FT. World Health Organization: International Agency for Research on Cancer.(2010). WHO classification of tumours of the digestive system. (Lyon: International Agency for Research on Cancer).

2. Nosho K, Igarashi H, Nojima M, Ito M, Maruyama R, Yoshii S, Naito T, Sukawa Y, Mikami M, Sumioka W, Yamamoto E, Kurokawa S, Adachi Y, Takahashi H, Okuda H, Kusumi T, et al. Association of microRNA-31 with BRAF mutation, colorectal cancer survival and serrated pathway. Carcinogenesis. 2014; 35:776-783.

3. Ito $M$, Mitsuhashi $K$, Igarashi $H$, Nosho $K$, Naito $T$, Yoshii S, Takahashi H, Fujita M, Sukawa Y, Yamamoto E, Takahashi T, Adachi Y, Nojima M, Sasaki Y, Tokino T, Baba $Y$, et al. MicroRNA-31 expression in relation to BRAF mutation, $\mathrm{CpG}$ island methylation and colorectal continuum in serrated lesions. Int J Cancer. 2014; 135:2507-2515.

4. Toiyama Y, Takahashi M, Hur K, Nagasaka T, Tanaka K, Inoue Y, Kusunoki M, Boland CR, Goel A. Serum miR-21 as a Diagnostic and Prognostic Biomarker in Colorectal Cancer. J Natl Cancer Inst. 2013; 105:849-859.

5. Meng X, Wu J, Pan C, Wang H, Ying X, Zhou Y, Yu H, Zuo Y, Pan Z, Liu RY, Huang W. Genetic and Epigenetic Down-regulation of MicroRNA-212 Promotes Colorectal 
Tumor Metastasis via Dysregulation of MnSOD. Gastroenterology. 2013; 145:426-436. e426.

6. Hur K, Toiyama Y, Takahashi M, Balaguer F, Nagasaka T, Koike J, Hemmi H, Koi M, Boland CR, Goel A. MicroRNA-200c modulates epithelial-to-mesenchymal transition (EMT) in human colorectal cancer metastasis. Gut. 2013; 62:1315-1326.

7. Schee K, Boye K, Abrahamsen TW, Fodstad O, Flatmark K. Clinical relevance of microRNA miR-21, miR-31, miR92a, miR-101, miR-106a and miR-145 in colorectal cancer. BMC Cancer. 2012; 12:505.

8. Pagliuca A, Valvo C, Fabrizi E, di Martino S, Biffoni M, Runci D, Forte S, De Maria R, Ricci-Vitiani L. Analysis of the combined action of miR-143 and miR-145 on oncogenic pathways in colorectal cancer cells reveals a coordinate program of gene repression. Oncogene. 2013; 32:4806-4813.

9. Mosakhani N, Sarhadi VK, Borze I, KarjalainenLindsberg ML, Sundstrom J, Ristamaki R, Osterlund P, Knuutila S. MicroRNA profiling differentiates colorectal cancer according to KRAS status. Genes Chromosomes Cancer. 2012; 51:1-9.

10. Ma Y, Zhang P, Wang F, Zhang H, Yang J, Peng J, Liu W, Qin H. miR-150 as a potential biomarker associated with prognosis and therapeutic outcome in colorectal cancer. Gut. 2012; 61:1447-1453.

11. Goel A, Boland CR. Epigenetics of colorectal cancer. Gastroenterology. 2012; 143:1442-1460. e1441.

12. Cekaite L, Rantala JK, Bruun J, Guriby M, Agesen TH, Danielsen SA, Lind GE, Nesbakken A, Kallioniemi O, Lothe RA, Skotheim RI. MiR-9, -31, and -182 deregulation promote proliferation and tumor cell survival in colon cancer. Neoplasia. 2012; 14:868-879.

13. Leidner RS, Ravi L, Leahy P, Chen Y, Bednarchik B, Streppel M, Canto M, Wang JS, Maitra A, Willis J, Markowitz SD, Barnholtz-Sloan J, Adams MD, Chak A, Guda K. The microRNAs, MiR-31 and MiR-375, as candidate markers in Barrett's esophageal carcinogenesis. Genes Chromosomes Cancer. 2012; 51:473-479.

14. Ueda T, Volinia S, Okumura H, Shimizu M, Taccioli C, Rossi S, Alder H, Liu CG, Oue N, Yasui W, Yoshida K, Sasaki H, Nomura S, Seto Y, Kaminishi M, Calin GA, et al. Relation between microRNA expression and progression and prognosis of gastric cancer: a microRNA expression analysis. Lancet Oncol. 2010; 11:136-146.

15. Creighton $\mathrm{CJ}$, Fountain $\mathrm{MD}, \mathrm{Yu} \mathrm{Z}$, Nagaraja $\mathrm{AK}$, Zhu H, Khan M, Olokpa E, Zariff A, Gunaratne PH, Matzuk MM, Anderson ML. Molecular profiling uncovers a p53-associated role for microRNA-31 in inhibiting the proliferation of serous ovarian carcinomas and other cancers. Cancer Res. 2010; 70:1906-1915.

16. Valastyan S, Reinhardt F, Benaich N, Calogrias D, Szasz AM, Wang ZC, Brock JE, Richardson AL, Weinberg RA. A pleiotropically acting microRNA,
miR-31, inhibits breast cancer metastasis. Cell. 2009; 137:1032-1046.

17. Meng F, Henson R, Wehbe-Janek H, Ghoshal K, Jacob ST, Patel T. MicroRNA-21 regulates expression of the PTEN tumor suppressor gene in human hepatocellular cancer. Gastroenterology. 2007; 133:647-658.

18. Schetter AJ, Leung SY, Sohn JJ, Zanetti KA, Bowman ED, Yanaihara N, Yuen ST, Chan TL, Kwong DL, Au GK, Liu CG, Calin GA, Croce CM, Harris CC. MicroRNA expression profiles associated with prognosis and therapeutic outcome in colon adenocarcinoma. JAMA. 2008; 299:425-436.

19. Toyota M, Ahuja N, Ohe-Toyota M, Herman JG, Baylin SB, Issa JP. CpG island methylator phenotype in colorectal cancer. Proc Natl Acad Sci U S A. 1999; 96:8681-8686.

20. Kusano M, Toyota M, Suzuki H, Akino K, Aoki F, Fujita M, Hosokawa M, Shinomura Y, Imai K, Tokino T. Genetic, epigenetic, and clinicopathologic features of gastric carcinomas with the $\mathrm{CpG}$ island methylator phenotype and an association with Epstein-Barr virus. Cancer. 2006; 106:1467-1479.

21. Weisenberger DJ, Siegmund KD, Campan M, Young J, Long TI, Faasse MA, Kang GH, Widschwendter M, Weener D, Buchanan D, Koh H, Simms L, Barker M, Leggett B, Levine J, Kim M, et al. CpG island methylator phenotype underlies sporadic microsatellite instability and is tightly associated with BRAF mutation in colorectal cancer. Nat Genet. 2006; 38:787-793.

22. Ueki T, Toyota M, Sohn $\mathrm{T}$, Yeo CJ, Issa JP, Hruban RH, Goggins M. Hypermethylation of multiple genes in pancreatic adenocarcinoma. Cancer Res. 2000; 60:1835-1839.

23. Fu T, Pappou EP, Guzzetta AA, Jeschke J, Kwak R, Dave P, Hooker CM, Morgan R, Baylin SB, Iacobuzio-Donahue CA, Wolfgang CL, Ahuja N. CpG island methylator phenotype-positive tumors in the absence of MLH1 methylation constitute a distinct subset of duodenal adenocarcinomas and are associated with poor prognosis. Clin Cancer Res. 2012; 18:4743-4752.

24. Noushmehr H, Weisenberger DJ, Diefes K, Phillips HS, Pujara K, Berman BP, Pan F, Pelloski CE, Sulman EP, Bhat KP, Verhaak RG, Hoadley KA, Hayes DN, Perou CM, Schmidt HK, Ding L, et al. Identification of a CpG island methylator phenotype that defines a distinct subgroup of glioma. Cancer Cell. 2010; 17:510-522.

25. Shen L, Ahuja N, Shen Y, Habib NA, Toyota M, Rashid A, Issa JP. DNA methylation and environmental exposures in human hepatocellular carcinoma. J Natl Cancer Inst. 2002; 94:755-761.

26. Suzuki M, Shigematsu H, Iizasa T, Hiroshima K, Nakatani Y, Minna JD, Gazdar AF, Fujisawa T. Exclusive mutation in epidermal growth factor receptor gene, HER-2, and KRAS, and synchronous methylation of nonsmall cell lung cancer. Cancer. 2006; 106:2200-2207. 
27. Tanemura A, Terando AM, Sim MS, van Hoesel AQ, de Maat MF, Morton DL, Hoon DS. CpG island methylator phenotype predicts progression of malignant melanoma. Clin Cancer Res. 2009; 15:1801-1807.

28. Abe M, Ohira M, Kaneda A, Yagi Y, Yamamoto S, Kitano Y, Takato T, Nakagawara A, Ushijima T. CpG island methylator phenotype is a strong determinant of poor prognosis in neuroblastomas. Cancer Res. 2005; 65:828-834.

29. Strathdee G, Appleton K, Illand M, Millan DW, Sargent J, Paul J, Brown R. Primary ovarian carcinomas display multiple methylator phenotypes involving known tumor suppressor genes. Am J Pathol. 2001; 158:1121-1127.

30. Maruyama R, Toyooka S, Toyooka KO, Virmani AK, Zochbauer-Muller S, Farinas AJ, Minna JD, McConnell J, Frenkel EP, Gazdar AF. Aberrant promoter methylation profile of prostate cancers and its relationship to clinicopathological features. Clin Cancer Res. 2002; 8:514-519.

31. Maruyama R, Toyooka S, Toyooka KO, Harada K, Virmani AK, Zochbauer-Muller S, Farinas AJ, Vakar-Lopez F, Minna JD, Sagalowsky A, Czerniak B, Gazdar AF. Aberrant promoter methylation profile of bladder cancer and its relationship to clinicopathological features. Cancer Res. 2001; 61:8659-8663.

32. Bae YK, Brown A, Garrett E, Bornman D, Fackler MJ, Sukumar S, Herman JG, Gabrielson E. Hypermethylation in histologically distinct classes of breast cancer. Clin Cancer Res. 2004; 10:5998-6005.

33. Figueroa ME, Abdel-Wahab O, Lu C, Ward PS, Patel J, Shih A, Li Y, Bhagwat N, Vasanthakumar A, Fernandez HF, Tallman MS, Sun Z, Wolniak K, Peeters JK, Liu W, Choe SE, et al. Leukemic IDH1 and IDH2 mutations result in a hypermethylation phenotype, disrupt TET2 function, and impair hematopoietic differentiation. Cancer Cell. 2010; 18:553-567.

34. Arai E, Chiku S, Mori $\mathrm{T}$, Gotoh $\mathrm{M}$, Nakagawa $\mathrm{T}$, Fujimoto H, Kanai Y. Single-CpG-resolution methylome analysis identifies clinicopathologically aggressive $\mathrm{CpG}$ island methylator phenotype clear cell renal cell carcinomas. Carcinogenesis. 2012; 33:1487-1493.

35. Ogino S, Nosho K, Kirkner GJ, Kawasaki T, Meyerhardt JA, Loda M, Giovannucci EL, Fuchs CS. CpG island methylator phenotype, microsatellite instability, BRAF mutation and clinical outcome in colon cancer. Gut. 2009; 58:90-96.

36. Nosho K, Irahara N, Shima K, Kure S, Kirkner GJ, Schernhammer ES, Hazra A, Hunter DJ, Quackenbush J, Spiegelman D, Giovannucci EL, Fuchs CS, Ogino S. Comprehensive biostatistical analysis of $\mathrm{CpG}$ island methylator phenotype in colorectal cancer using a large population-based sample. PLoS One. 2008; 3:e3698.

37. Nosho $\mathrm{K}$, Yamamoto $\mathrm{H}$, Takahashi $\mathrm{T}$, Mikami M, Taniguchi H, Miyamoto N, Adachi Y, Arimura Y, Itoh F,
Imai K, Shinomura Y. Genetic and epigenetic profiling in early colorectal tumors and prediction of invasive potential in pT1 (early invasive) colorectal cancers. Carcinogenesis. 2007; 28:1364-1370.

38. Zhang XF, Li KK, Gao L, Li SZ, Chen K, Zhang JB, Wang D, Tu RF, Zhang JX, Tao KX, Wang G, Zhang XD. miR-191 promotes tumorigenesis of human colorectal cancer through targeting C/EBPbeta. Oncotarget. 2015; 6:4144-4158.

39. Fang L, Li H, Wang L, Hu J, Jin T, Wang J, Yang BB. MicroRNA-17-p promotes chemotherapeutic drug resistance and tumour metastasis of colorectal cancer by repressing PTEN expression. Oncotarget. 2014; 5:2974-2987.

40. Bullock MD, Pickard K, Mitter R, Sayan AE, Primrose JN, Ivan C, Calin GA, Thomas GJ, Packham GK, Mirnezami AH. Stratifying risk of recurrence in stage II colorectal cancer using deregulated stromal and epithelial microRNAs. Oncotarget. 2015; 6:7262-7279.

41. Manceau G, Imbeaud S, Thiebaut R, Liebaert F, Fontaine K, Rousseau F, Genin B, Le Corre D, Didelot A, Vincent M, Bachet JB, Chibaudel B, Bouche O, Landi B, Bibeau F, Leroy $\mathrm{K}$, et al. Hsa-miR-31-3p expression is linked to progression-free survival in patients with KRAS wildtype metastatic colorectal cancer treated with anti-EGFR therapy. Clin Cancer Res. 2014; 20:3338-3347.

42. Igarashi $\mathrm{H}$, Kurihara $\mathrm{H}$, Mitsuhashi K, Ito M, Okuda H, Kanno S, Naito T, Yoshii S, Takahashi H, Kusumi T, Hasegawa T, Sukawa Y, Adachi Y, Okita K, Hirata K, Imamura $Y$, et al. Association of MicroRNA-31-5p with Clinical Efficacy of Anti-EGFR Therapy in Patients with Metastatic Colorectal Cancer. Ann Surg Oncol. DOI: 10.1245/s10434-014-4264-7. in press.

43. Yan W, Zhang W, Sun L, Liu Y, You G, Wang Y, Kang C, You Y, Jiang T. Identification of MMP-9 specific microRNA expression profile as potential targets of antiinvasion therapy in glioblastoma multiforme. Brain Res. 2011; 1411:108-115.

44. Hur K, Toiyama Y, Schetter AJ, Okugawa Y, Harris CC, Boland CR, Goel A. Identification of a metastasis-specific MicroRNA signature in human colorectal cancer. J Natl Cancer Inst. 2015; 107.

45. Iino I, Kikuchi H, Miyazaki S, Hiramatsu Y, Ohta M, Kamiya K, Kusama Y, Baba S, Setou M, Konno H. Effect of miR-122 and its target gene cationic amino acid transporter 1 on colorectal liver metastasis. Cancer Sci. 2013; 104:624-630.

46. Hughes LA, Melotte V, de Schrijver J, de Maat M, Smit VT, Bovee JV, French PJ, van den Brandt PA, Schouten LJ, de Meyer T, van Criekinge W, Ahuja N, Herman JG, Weijenberg MP, van Engeland M. The CpG island methylator phenotype: what's in a name? Cancer Res. 2013; 73:5858-5868. 
47. Ogino S, Nosho K, Kirkner GJ, Shima K, Irahara N, Kure S, Chan AT, Engelman JA, Kraft P, Cantley LC, Giovannucci EL, Fuchs CS. PIK3CA mutation is associated with poor prognosis among patients with curatively resected colon cancer. J Clin Oncol. 2009; 27:1477-1484.

48. Nosho K, Igarashi H, Ito M, Mitsuhashi K, Kurihara H, Kanno S, Yoshii S, Mikami M, Takahashi H, Kusumi T, Hosokawa M, Sukawa Y, Adachi Y, Hasegawa T, Okita K, Hirata K, et al. Clinicopathological and molecular characteristics of serrated lesions in Japanese elderly patients. Digestion. 2015; 91:57-63.

49. Irahara N, Baba Y, Nosho K, Shima K, Yan L, Dias-Santagata D, Iafrate AJ, Fuchs CS, Haigis KM, Ogino S. NRAS mutations are rare in colorectal cancer. Diagn Mol Pathol. 2010; 19:157-163.

50. Liao X, Lochhead P, Nishihara R, Morikawa T, Kuchiba A, Yamauchi M, Imamura Y, Qian ZR, Baba Y, Shima K, Sun R, Nosho K, Meyerhardt JA, Giovannucci E, Fuchs CS, Chan AT, et al. Aspirin use, tumor PIK3CA mutation, and colorectal-cancer survival. N Engl J Med. 2012; 367:1596-1606.

51. McShane LM, Altman DG, Sauerbrei W, Taube SE, Gion M, Clark GM. Reporting recommendations for tumor marker prognostic studies (REMARK). J Natl Cancer Inst. 2005; 97:1180-1184.

52. Mitsuhashi K, Nosho K, Sukawa Y, Matsunaga Y, Ito M, Kurihara H, Kanno S, Igarashi H, Naito T, Adachi Y, Tachibana M, Tanuma T, Maguchi H, Shinohara T, Hasegawa $\mathrm{T}$, Imamura $\mathrm{M}$, et al. Association of Fusobacterium species in pancreatic cancer tissues with molecular features and prognosis. Oncotarget. 2015; 6:7209-7220.

53. Ogino S, Kawasaki $\mathrm{T}$, Brahmandam $\mathrm{M}$, Cantor $\mathrm{M}$, Kirkner GJ, Spiegelman D, Makrigiorgos GM, Weisenberger DJ, Laird PW, Loda M, Fuchs CS. Precision and performance characteristics of bisulfite conversion and real-time PCR (MethyLight) for quantitative DNA methylation analysis. J Mol Diagn. 2006; 8:209-217. 